\title{
Genetics of inflammatory bowel disease
}

\author{
J Satsangi, D P Jewell, W M C Rosenberg, J I Bell
}

\section{Introduction}

The aetiology and pathogenesis of the chronic inflammatory bowel diseases, Crohn's disease and ulcerative colitis, remain under investigation. It has become accepted that disease occurs in a genetically susceptible subject, as a result of the interaction between antigenic stimulus and the cells of the immune system. As a preliminary to a collaborative study of the immunogenetics of inflammatory bowel disease we have examined critically the evidence that genetic factors contribute to disease susceptibility.

A fundamental issue is the relation between Crohn's disease and ulcerative colitis. Although the classification of these conditions together is convenient, its scientific basis is not proved. We suggest that inflammatory bowel disease represents a number of distinct conditions of multifactorial aetiology. Some, but not all, predisposing genetic and environmental factors may be shared between subtypes of disease. Present knowledge of the extent of disease heterogeneity, however, is incomplete: this has contributed to the difficulty in defining the genetic basis of inflammatory bowel disease.

\section{Evidence for genetic predisposition}

A number of lines of study may be cited to show that genetic predisposition is important in susceptibility to inflammatory bowel disease, especially Crohn's disease. These include studies of disease prevalence in ethnic groups and migrants, and of the familial occurrence of disease. Critical review of these data suggest genetic factors interact with environmental factors: the comparative importance of nature and nurture is unclear.

\section{Department of Gastroenterology, Radcliffe Infirmary, Oxford \\ J Satsangi, \\ D P Jewell}

Nuffield Department of Clinical Medicine, John Radcliffe Hospital, Oxford Oxford J I Bell

Correspondence to: Dr D P Jewell, Gastroenterology Unit, Radcliffe Infirmary Woodstock Road, Oxford OX2 6HE.

Accepted for publication 28 July 1993 ETHNIC AND MIGRANT GROUPS

Considerable differences exist in the prevalence of inflammatory bowel disease between different racial and ethnic groups. Crohn's disease and ulcerative colitis are most common in white people: lower prevalence rates are reported for native Americans, black Americans, Latin Americans, Maoris, and Asians. ${ }^{1}$ Among white groups, the ethnic group with the highest incidence and prevalence of inflammatory bowel disease are the Ashkenazic Jews of western Europe, United States, and Cape Town. ${ }^{2}$

Disease prevalence has been studied in Jewish migrants to Israel, ${ }^{2}$ and Asian migrants to the United Kingdom. ${ }^{34}$ In Israel, the Ashkenazic
Jews who have migrated from Europe continue to show an increased disease prevalence, compared with the Sephardic Jews from north Africa and the Middle East. The overall prevalence of inflammatory bowel disease in Tel Aviv (in all ethnic groups), however, is much lower than that reported in western European or North American cities. ${ }^{2}$

In the United Kingdom, the incidence and prevalence of inflammatory bowel disease has been studied in Asian migrants, and their offspring, who have settled in industrial cities (London, ${ }^{3}$ Bradford,${ }^{4}$ Leicester ${ }^{5}$ ). These studies suggest that these immigrants have an increased susceptibility to inflammatory bowel disease, compared with Asians resident in Asia. In particular, ulcerative colitis seems more prevalent in South Asians in Leicester, than in the native white population. ${ }^{5}$

Environmental together with genetic factors are implicated by these studies: it does seem that both contribute to the development of all phenotypes of inflammatory bowel disease.

\section{FAMILIAL INFLAMMATORY BOWEL DISEASE}

Many studies, using differing methodologies, have shown an increased prevalence of inflammatory bowel disease among relative of patients with Crohn's disease and ulcerative colitis. First degree relatives are at the greatest risk, particularly siblings, but more distant relatives also display an increased prevalence of disease. Both Crohn's disease and ulcerative colitis may occur in the same family.

The prevalence of a positive family history is uncertain, as the estimates vary considerably from study to study. Many of the data implying high disease prevalence in first degree relatives may be criticised for using selected patient groups.

Farmer $e t a l^{6}$ have reported the highest preval- ence of affected relatives, in a study based at the Cleveland Clinic. Of 522 patients with Crohn's disease, $187(35 \cdot 2 \%)$ were shown to have an affected family member (87 (16.7\%) first degree). Of 316 ulcerative colitis patients $29 \cdot 4 \%$ had a positive family history $(50(15 \cdot 8 \%)$ first degree). These data include, however, only patients with onset of disease before 21 years of age. If either ulcerative colitis or Crohn's disease represents a number of genetically different conditions, then disease with an early age of onset may represent a subgroup with a particularly strong genetic influence.

A number of reports showing a high preval- 
ence of familial inflammatory bowel disease have included Ashkenazic Jews of the United States. ${ }^{78}$ This bias has been recognised; recently Yang et $a l^{9}$ have attempted to define the precise risks of inflammatory bowel disease in relatives of Jewish and non-Jewish patients, cared for in southern California. Five hundred and twenty seven patients (291 Jews; 236 non-Jewish) were questioned. Age specific incidence data were used to estimate lifetime risks. In the first degree relatives of non-Jewish probands, the lifetime risks for inflammatory bowel disease were $5 \cdot 2$ and $1.6 \%$, when probands had Crohn's disease and ulcerative colitis respectively. These values were consistently lower than the corresponding risks for relatives of Jewish patients $(7 \cdot 8$ and $4 \cdot 5 \%$ respectively).

McConnell has studied the family histories of 336 patients attending Broadgreen Hospital, in Liverpool. ${ }^{10}$ Thirty one $(18 \cdot 8 \%)$ of 165 patients with Crohn's disease had an affected first degree relative: in 27 cases, a sibling was affected. Of patients with ulcerative colitis, 20 of 171 had a positive family history (14.6\%): in 16 cases, a sibling was affected. It was more probable that relatives of Crohn's disease patients would have Crohn's disease than ulcerative colitis, but both diseases were present in many families.

We have recently reviewed the family histories of patients with Crohn's disease and ulcerative colitis attending the gastroenterology clinic in Oxford. Case notes were reviewed. Of 317 patients with Crohn's disease, 41 (13\%) have a positive family history for inflammatory bowel disease. In 21 cases, the affected relative is a sibling $(6.6 \%)$. Of 825 patients with ulcerative colitis, $90(12 \%)$ have a positive family history. In $31(3 \cdot 75 \%)$, a sibling is affected; in $24(2 \cdot 9 \%)$ parents are affected.

Environmental factors are common to first degree relatives sharing the same home. Van Kruiningen et al propose that shared environmental stimulus accounts for familial Crohn's disease, with particular reference to two large French families, with many affected relatives." Disease is not common, however, in spouses of patients with inflammatory bowel disease, whereas blood relatives separated by geography and generations retain an increased prevalence of Crohn's disease and ulcerative colitis.

\section{TWIN STUDIES}

The argument that genetic factors are of importance in the pathogenesis of inflammatory bowel disease, particularly Crohn's disease, is reinforced by studies of twins. Most pertinent is the survey of the Swedish registry of twin births. ${ }^{12}$ Eighty twin pairs were identified in which at least one twin was known to have inflammatory bowel disease. All twins were brought up in the same environment. Eight of 18 monozygotic twin pairs were concordant for Crohn's disease, but only one of 26 dizygotic pairs. In the twin pairs with one proband having ulcerative colitis, one of 16 monozygotic twins were concordant for the disease, but all other 20 twin pairs (dizygotic or unknown zygosity) were discordant. No 'mixed disease' twin pair, either monozygotic or dizygotic, was reported in this study.

The concordance of monozygotic twins for Crohn's disease is strong evidence for genetic susceptibility in this form of inflammatory bowel disease. The calculated heritability for Crohn's disease in this twin study was greater than values reported for diabetes, duodenal ulcer, schizophrenia, hypertension or bronchial asthma. Furthermore, the differences in concordance rates between Crohn's disease and ulcerative colitis, and the absence in published works of a mixed disease twin pair suggest that these phenotypes of inflammatory bowel disease have a distinct genetic basis.

\section{ANKYLOSING SPONDYLITIS AND PRIMARY}

SCLEROSING CHOLANGITIS

Ankylosing spondylitis, ${ }^{13}$ and primary sclerosing cholangitis $^{14}$ are recognised to have strong associations with distinct HLA specificities (HLA-B27 and B8 DR3 respectively), although the pathogenesis of both diseases awaits clarification. Both ankylosing spondylitis and primary sclerosing cholangitis occur more frequently than predicted in patients with inflammatory bowel disease and their first degree relatives. The mechanism underlying the association is uncertain. In the absence of ankylosing spondylitis, or sclerosing cholangitis, HLA-B27 and HLA-B8 DR3 are not associated with inflammatory bowel disease.

\section{Pathophysiology and genetic susceptibility}

If genetic susceptibility is important in the pathogenesis of chronic inflammatory bowel disease, what physiological process is affected? This problem remains unsolved, although recent investigations have pointed at aspects of nonspecific defence mechanisms as well as the regulation of the antigen specific immune response.

\section{NON-SPECIFIC DEFENCE MECHANISMS}

Hollander et al showed increased intestinal permeability in 11 patients with Crohn's disease, and their 32 healthy first degree relatives, using the marker polyethylene glycol $400 .{ }^{15}$ These workers propose that this abnormality permits increased antigen uptake from the gut lumen, providing the stimulus for chronic inflammation. Although this is an area of considerable controversy, ${ }^{16}$ these initial findings have received recent support. ${ }^{17}$

The complement system, which may participate in the non-specific and specific immune response, has also been examined in Crohn's disease. Earlier work ${ }^{18}$ suggesting an association between $\mathrm{F}$ allotype of $\mathrm{C} 3$ and small bowel Crohn's disease (but not ulcerative colitis) has been supplemented by the finding of an enhanced production of complement components by the small intestine in healthy first degree relatives of probands with Crohn's disease. ${ }^{19}$ Compared with healthy unrelated controls, relatives had a $40 \%$ increase in jejunal fluid concentration of $\mathrm{C} 4$. Concentrations of $\mathrm{C} 3$ and 
factor B were similar in healthy relatives and controls. These results, if reproducible, would imply that a primary (quantitative or qualitative) abnormality of complement secretion may contribute to the chronic inflammation of Crohn's disease.

The mucin glycoproteins of the small and large intestinal mucosa are thought to play an important part in the normal intestinal function, and in non-specific defence mechanisms. ${ }^{20}$ Using monoclonal antibodies directed against human colonic determinants, and detailed structural analysis, Podolsky et $a l^{21}$ have classified human mucin glycoprotein species I to VI. These may reflect the products of functionally distinct subpopulations of colon goblet cells. Mucin isolated from colonic tissue from patients with Crohn's disease contained subclasses in similar proportions to those seen in normal controls. Mucin glycoproteins from patients with ulcerative colitis, however, were selectively deficient in subclass IV.$^{22}$ Recently evidence has emerged to suggest that this deficiency may be a primary mechanism, increasing host susceptibility to disease. ${ }^{23}$ In monozygotic twin pairs, in which one sibling had ulcerative colitis, both siblings had reduced mucin subclass IV.

Molecular genotyping of mucin and complement genes is now available; these loci provide candidate genes for association studies, and linkage analysis (see below).

\section{Genetics and the immune response}

The activated cells of the immune system and their products are central to the pathogenesis of inflammatory bowel disease. Whether the chronic inflammatory response is an appropriate consequence of stimulation by exogenous antigen or a primary (genetically determined) defect of immunoregulation is uncertain. The second possibility has stimulated research into all aspects of immune function in patients with inflammatory bowel disease.

The key interaction in the generation of the specific immune response is that between the $T$ cell receptor for antigen and the antigenic peptide, presented in the context of HLA molecules on the cell surface of antigen presenting cells. Processed antigen, presented in the context of class I HLA antigens will stimulate clonal proliferation and differentiation of specific cytotoxic lymphocytes. In contrast, 'helper' $T$ cells will recognise antigen only in the context of class II antigens.

\section{THE HLA SYSTEM}

The structure of the glycoprotein molecules that make up class I and class II antigens is genetically encoded in the major histocompatibility complex on the short arm of chromosome six. Molecular analysis has established that these genes display a high degree of allelic polymorphism, not shown by serological methods alone.

A large number of investigators have sought association between ulcerative colitis and Crohn's disease and allelic variations in the genes of the major histocompatibility complex. In retrospect, methodological discrepancies are evident, particularly the reliance on serological typing of histocompatibility antigens rather than molecular genotyping. Early studies were hampered by incomplete knowledge of the HLA system, inadequate controls for ethnic differences, and small numbers of patients studied.

With the exception of patients also having ankylosing spondylitis, or primary sclerosing cholangitis noted above, the results have been largely inconclusive. No consistent HLA association has been reported ${ }^{24}$ using serological techniques in Crohn's disease, although meta analysis of published results of 730 pooled white patients showed that HLA-A2 allele carries a comparative risk of $1 \cdot 25$, whereas HLA-A 11 has a significant negative association. ${ }^{25}$

For ulcerative colitis, seven studies using serological techniques ${ }^{26-32}$ have shown an increase in frequency of HLA-DR2 allele, although only two reached statistical significance. ${ }^{2632}$ The most recent studies of class II association have been designed successfully to overcome earlier difficulties, and provide encouragement. Toyoda $e t a l^{33}$ have conducted an association study using carefully selected ethnically matched cases and controls, and a combination of molecular and serological techniques. The authors show separate genetic susceptibilities for Crohn's disease and ulcerative colitis. The haplotype HLA-DR1 $\mathrm{DQ}_{w 5}$ was present in $27 \%$ of patients with Crohn's disease, compared with $13 \%$ controls $(\mathrm{p}=0.021)$. In contrast, HLA-DR2 was found to be present in $41 \%$ of patients with ulcerative colitis, compared with $21 \%$ controls, a statistically significant difference. Negative associations with DR4 and $\mathrm{DR}_{\mathrm{w} 6}$ were found in ulcerative colitis.

Although the early studies of HLA association with inflammatory bowel disease are generally regarded as inconclusive, it is relevant, in the light of this recent study, to re-evaluate them, and consider if particular phenotypes of disease may have defined genotypic association. The data from McConnell et al, ${ }^{27}$ and Asakura et $a l^{26}$ both show that the association of HLA-DR2 is most pronounced with cases with total colonic involvement. Hence, specific genetic associations with phenotypically distinct subclasses of disease (for example, total colitis, proctitis) may be hidden, if ulcerative colitis is treated as genetically homogenous. Even if clinically apparent phenotypes of disease do not have a distinct genetic basis, subclasses may be defined by subclinical markers. Considerable recent interest concerns the use of the anti-neutrophil cytoplasmic antibody (ANCA) in defining subclasses of ulcerative colitis that are ANCA positive and ANCA negative. At present, however, results from North American ${ }^{34}$ and western European $^{35}$ centres show marked discrepancies.

\section{NON-HLA GENES}

There are a number of non-HLA genes participating in the immune response. The genes that encode immunoglobulins and cytokines display allelic polymorphisms, which may be important in immunogenetic susceptibility to immune mediated disease. Of particular interest are the 
genes encoding the chains of the antigen receptor on the cell surface of $T$ lymphocytes. ${ }^{36}$ This comprises two variable clonally distributed glycoproteins (either an $\alpha \beta$ or $\gamma \delta$ pair). The $\alpha, \beta$, $\gamma, \delta$ chains are members of the immunoglobulin supergene family. Each protein chain has identifiable variable $(v)$, joining $(j)$, and constant (c) regions ( $\beta$ and $\delta$ chains also incorporate a diversity region (d) between $v$ and $j$ ). The genes encoding these chains consist of a variable number of distinct segments representing the regions of the protein. Recombination of these segments permits for considerable diversity of $\mathbf{T}$ cell receptor structure (fully reviewed in reference 36). These genes are highly polymorphic and alleles may be defined by restriction fragment length polymorphisms (RFLP), or tandem repeat sequences. Preliminary studies have sought associations between alleles defined by RFLP and inflammatory bowel disease. Markers in the constant regions of both $\alpha$ and $\beta$ chains have been investigated..$^{33738}$ These studies are profoundly limited by the failure to consider the lack of linkage disequilibrium across the region.

The repertoire of antigen receptors expressed on peripheral lymphocytes is determined not only by the diversity permitted by the $T$ cell receptor genes, but also depends on subsequent events, notably intrathymic selection and deletion. Recent studies have indirectly implicated class II antigens and non-inherited maternal HLA antigens in determining expressed $\mathrm{T}$ cell repertoire in diabetes mellitus ${ }^{39}$ and rheumatoid arthritis ${ }^{40}$ respectively. Posnett et $a l^{41}$ have shown oligoclonal T cell populations in mesenteric lymph nodes from resected specimens from Crohn's disease patients. This oligoclonality of $\mathrm{V} \beta$ receptor expression was not linked to a known polymorphism of the $\mathrm{V} \beta$ gene. Other workers are also exploring the expressed $\mathrm{T}$ cell repertoire in Crohn's disease. ${ }^{42}$

\section{LINKAGE ANALYSIS}

Advances in molecular biology have increased our ability to define accurately disease associations with alleles at a given genetic locus. Although association studies may help in our understanding of the heterogeneity of inflammatory bowel disease and of the relation between ulcerative colitis and Crohn's disease, these population based studies are of limited use in precisely locating susceptibility genes. False positive associations may arise because of the use of an inappropriate control population; moreover, the gene identified in an association study may simply be in linkage disequilibrium with a true susceptibility gene.

To identify a true susceptibility gene, it is necessary to show linkage between disease and a candidate gene: inheritance of the gene must be shown to be significantly linked to disease inheritance.

In addition to the methodological difficulties inherent in association studies, linkage analysis provides fresh problems. To gain adequate statistical power, access is required to a large number of informative families, in which there is a strong history of inflammatory bowel disease.
Furthermore, parametric methods of linkage analysis are most relevant to diseases in which the mode of inheritance, and extent of disease heterogeneity are clearly defined. In the light of these problems, detailed linkage analysis has not been carried out in inflammatory bowel disease, although a few small studies have been published (reviewed briefly in reference 24). The results of these early investigations do not permit accurate assessment of the overall genetic contribution to disease susceptibility.

At present independent investigators in the United States and Great Britain (in London and Oxford) are concentrating on the establishment of a repository of genetic material from inflammatory bowel disease families. Once this resource is available, formal linkage analysis using parametric and non-parametric methods (affected sibling pair) will be possible. As discussed, a number of candidate genes have presented themselves, in particular HLA class II, T cell receptors, complement, and mucin genes. It is hoped to evaluate accurately the contribution of these loci to overall disease susceptibility (as is already possible in a number of 'oligogenic diseases'). ${ }^{43}$

\section{Genetic heterogeneity and inflammatory bowel disease}

In conclusion, the classification of Crohn's disease together with ulcerative colitis as inflammatory bowel disease is convenient, but has a limited proved aetiopathological basis. Distinct pathological and physiological differences have been shown between these conditions, and genetic marker studies now also suggest distinct susceptibility. Any model proposed to explain disease inheritance, however, must also explain the fact that both diseases may coexist in one pedigree.

Crohn's disease and ulcerative colitis probably do not have a simple Mendelian mode of inheritance. The empiric risk to siblings and offspring shown in the familial studies are not in keeping with autosomal dominant or recessive inheritance. Complex segregation analysis, carried out on German ${ }^{44}$ and Scandinavian ${ }^{45}$ populations has suggested that a simple autosomal gene may be operating only in small subgroups of inflammatory bowel disease patients. Most recently, Orholm et al assessed patterns of disease segregation in 637 Danish patients and their relatives. ${ }^{45}$ Analysis suggested an important dominant gene with a penetrance of $0.20-0.26$ in $9-13 \%$ of adult patients with ulcerative colitis. For Crohn's disease, an autosomal recessive model was relevant in $7 \%$ of families.

An alternative model is the 'multiple loci single disease model', applied to explain the familial association of Crohn's disease and ulcerative colitis.' This model suggests that one genotype, with perhaps 10 to 15 genes, confers susceptibility to all forms of inflammatory bowel disease. If a person has an incomplete genotype, ulcerative colitis is more probable; if the genotype is complete Crohn's disease occurs. This model would account for the prevalence of ulcerative colitis in families of probands with Crohn's disease, and the stronger family history 
of Crohn's disease. The model assumes, however, that Crohn's disease and ulcerative colitis are a single disease entity: this is not supported by the recent genetic marker studies.

We conclude that the ethnic, familial, twin, disease association, and genetic marker studies are best explained by the concept of inflammatory bowel disease as a group of multifactorial diseases. Environmental and genetic factors contribute to disease susceptibility. A number of susceptibility genes participate in each subtype of inflammatory bowel disease: some may be shared between different subtypes, and some distinct. The number of subtypes is not certain: Toyoda et $a l^{31}$ consider that the minimum number is three. It is possible that different susceptibility genes may underlie phenotypic differences in inflammatory bowel disease. Subclinical markers may also be of use.

It is important to define the extent of disease heterogeneity. Investigation of genetic markers by linkage analysis and association studies may help to do so.

J Satsangi is an MRC Training Fellow. The authors are grateful to Professor J Lennard-Jones for helpful discussion. Miss C E Cullen prepared the typescript.

1 McConnell RB, Vadheim CM. Inflammatory bowel disease. In: King RA, Rotter JI, Motulsky AO, eds. The genetic basis of common diseases. Oxford: Oxford University Press, 1992: of common

2 Gilat T, Grossman A, Fireman Z, Rosen P. Inflammatory bowel disease in Jews. In: McConnell R, Rozen P, Langman $M$, Gilat $T$, eds. The genetics and epidemiology of inflammatory bowel disease. Basel, New York: Karger, 1986: 135-40.

3 Chong SKF, Walker-Smith JA. Chronic inflammatory bowel disease in immigrants in the United Kingdom. In: genetics and epidemiology of inflammatory bowel disease. Basel, New York: Karger, 1986: 129-32.

4 Findlay JM, Jayarantne SD. Chronic inflammatory bowel disease in immigrants in the United Kingdom. In: McConnell $\mathrm{R}$, Rozen $\mathrm{P}$, Langman $\mathrm{M}$, Gilat $\mathrm{T}$, eds. The genetics and epidemiology of inflammatory bowel disease. Basel, New York: Karger, 1986: 124-9.

5 Probert CSJ, Jayanthi V, Pinder D, Wicks AC, Mayberry JF. Epidemiological study of ulcerative proctocolitis in Indian migrants and the indigenous population of Leicestershire. Gut 1992; 33: 687-93.

6 Farmer RG, Michener WM, Mortimer EA. Studies of family history among patients with inflammatory bowel disease. Clin Gastroenterol 1980; 9: 271-7.

7 Singer HC, Anderson JGD, Frischer H, Kirsner JB. Familial aspects of inflammatory bowel disease. Gastroenterology $1971 ; 61$ : 423-30.

8 Roth M-P, Petersen GM, McElree C, Vadheim CM, Panish JF, Rotter JI. Familial recurrence risk estimates of inflammatory bowel disease in Ashkenazi Jews. Gastroenterology 1989; 96: 1016-20.

9 Yang H, McElree C, Roth M-P, Shanahan F, Targan SR Rotter JI. Familial empirical risks for inflammatory bowel disease: differences between Jews and non-Jews. Gut 1993; 34: 517-24.

10 McConnell RB. Genetics of inflammatory bowel disease. In: Allan RN, Keighley MRB, Alexander-Williams J, Hawkins $\mathrm{C}$, eds. Inflammatory bowel disease. 2nd ed. Edinburgh Churchill-Livingstone, 1990: 11-23.

11 Van Kruiningen HJ, Colombel JF, Cartun RW, Whitlock RH, Koopmans M, Kangro HO, et al. An in depth study of Crohn's disease in two French families. Gastroenterology 1993; 104: 351-60.

12 Tysk C, Lindberg E, Järnerot G, Flodérus-Myrhed. Ulcerative colitis and Crohn's disease in an unselected population of monozygotic and dizygotic twins. A study of heritability of monozygotic and dizygotic twins. A study of herit
and the influence of smoking. Gut 1988; 29: 990-6.

13 Russell AS. Arthritis, inflammatory bowel disease, and histocompatibility antigens. Ann Intern Med 1977; 86: 820-1.

14 Chapman RW. Aetiology and natural history of primary sclerosing cholangitis: a decade of progress? Gut 1991; 32: 1433-5.

15 Hollander D, Vadheim CM, Brettholz E, Petersen GM, Delahunty T, Rotter JI. Increased intestinal permeability in patients with Crohn's disease and their relatives - a possible aetiological factor. Ann Intern Med 1986; 105: 883-5.

16 Hollander D. Permeability in Crohn's disease: altered barrier functions in healthy relatives? Gastroenterology 1993; 104: 1848-51.

17 May GR, Sutherland LR, Meddings JB. Is small intestinal permeability really increased in relatives of patients with Crohn's disease? Gastroenterology 1993; 104: 1627-32.

18 Elmgreen J, Sorensen W, Berkowicz A. Polymorphism of complement $\mathrm{C} 3$ in chronic inflammatory bowel disease. Acta Med Scand 1984; 215: 375-8.

19 Adrenstedt O, Knutson L, Nilsson B, Nillson-Ekdahl K, Huallgen R. Enhanced production of complement components by the small intestine in first degree relatives of Crohn's disease patients. Gastroenterology 1991; 100: A555.

20 Tytgat KM, Dekker J, Büller HA. Mucins in inflammatory bowel disease. Eur f Gastroenterol Hepatol 1993; 5: 119-27.

21 Podolsky DK, Fournier DA, Lynch KE. Development of anti-human colonic mucin monoclonal antibodies: characterisation of multiple colonic mucin species. $\mathcal{F}$ Clin Invest 1986; 77 : 1251-61.

22 Podolsky DK, Isselbacher KJ. Glycoprotein composition of colonic mucosa. Spoecific alterations in ulcerative colitis. colonic mucosa. Spoecific altera
Gastroenterology 1984; 87: $991-8$.

23 Tysk C, Riedesel H, Lindberg E, Panzini B, Podolsky D, Järnerot G. Colonic glycoproteins in monozygotic twins with inflammatory bowel disease. Gastroenterology 1991; 100: 419-23.

24 Shohat T, Vadheim CM, Rotter JI. The genetics of inflammatory bowel diseases. In: Gitnick G, ed. Inflammatory bowel disease: a physicians guide. New York: Igaku-Shoin, 1992; 53-86.

25 Biemond I, Burnham WR, D'Amaro J, Langman MJS. HLA-A and -B antigens in inflammatory bowel disease. Gut 1986; 27: 934-41.

26 Asakura H, Tsuchiya M, Aiso S, et al. Association of human lymphocyte-DR2 antigen with Japanese ulcerative colitis. Gastroenterology 1982; 82: 413-8.

27 McConnell RB. Ulcerative colitis - genetics feature. Scand $\mathcal{F}$ Gastroenterol 1983; 18 (suppl 88): 14.1.

28 Smolen JS, Gangl A, Poltrauer P, Menzel EJ, Mayr WR. HLA antigens in inflammatory bowel disease. Gastroenterology 1982; 82: 34-8.

29 Burnham WR, Gelsthorpe K, Langman MJS. HLA-D related antigens in inflammatory bowel disease. In: Pena AS, Weterman IT, Booth CC, Strober W, eds. Recent advances in Crohn's disease. The Hague: Martinus Nijhoff, 1981: 192-6.

30 Cottone $M$, Bunce $M$, Taylor CJ, Ting A, Jewell DP. Ulcerative colitis and HLA phenotype. Gut 1985; 26: 952-4.

31 Caruso C, Palmeri P, Oliva L, Orlando A, Cottone M. HLA antigens in ulcerative colitis: A study in the Sicilian populaantigens in ulcerative colitis: A study
tion. Tissue Antigens 1985; 25: 47-9.

32 Kobayashi K, Atoh M, Konoeda Y, Inoko H, Sekiguchi S HLA-DR, DQ and T cell antigen receptor constant beta genes in Japanese patients with ulcerative colitis. Clin Exp Immunol 1990; 80: 400-3.

33 Toyoda H, Wang S-J, Yang H, Redford A, Magalong D, Tyan D, et al. Distinct association of HLA Class II genes with inflammatory bowel disease. Gastroenterology 1993 104: 741-8.

34 Shanahan F, Duerr R, Rotter JI, Yang H, Sutherland L, et al. Neutrophil auto-antibodies in ulcerative colitis: familial aggregation and genetic heterogeneity. Gastroenterology 1992; 103: 456-61.

35 Reumaux D, Delecourt L, Colombel JF, Duthilleul P, GowerRousseau C, Noel LH, et al. Prevalence of ANCA in first degree relatives of patients with ulcerative colitis. Gastrodegree relatives of patients
enterology 1992; 102: A683.

36 Moss PAH, Rosenberg WMC, Bell JI. The human T cell receptor in health and disease. Ann Rev Immunol 1992; 10: 71-96.

37 Randolph LM, Toyoda H, McElree CK, Shanahan F, Targan SP, Rotter JI. Absence of the Eco-RV T cell receptor alphachain 10-Kb RFLP in ulcerative colitis. Gastroenterology 1989; 7: 1115-20.

38 Katakura S, Einarsson L, Hammarström L, Smith C. Restriction fragment length polymorphism analysis of $\mathrm{T}$ cell receptor genes in inflammatory bowel disease. Scand $\mathcal{f}$ Gastroenterol 1989; 24: 381-4.

39 Kelly $\mathbf{H}$, Garlepp MJ. T cell receptor haplotypes in families of patients with insulin-dependent diabetes mellitus. Clin Exp patients with insulin-depender

40 ten Wolde S, Breedveld FC, de Vries RRP, D'Amaro J, Rubenstein P, Schreuder GM Th, et al. Influence of noninherited maternal HLA antigens on occurrence of rheumatoid arthritis. Lancet 1993; 341: 200-2.

41 Posnett DN, Schmelkin I, Burton DA, August A, McGrath $\mathrm{H}$, Mayer LF. T cell antigen receptor $V$ gene usage increases in VB $8 \mathrm{~T}$ cell usage in Crohn's disease. I Clin Invest 1990; 85: 1770-6.

42 Lowes JR, Chahal H, Zewde M, Allan RN, Ibbotson JP. T cell receptor V $\beta$ gene usage in mesenteric lymph node mononuclear cell populations from

43 Rotter JI, Landaw EM. Measuring the genetic contribution of a single locus to a multi-locus disease. Clin Genet 1984; 26: a single

44 Kuster W, Pascoe L, Purrman J, Funk S, Majewski F. The genetics of Crohn's disease: complex segregation analysis of a family study with 265 patients with Crohn's dise

45 Orholm M, Iselius L, Sorensen T, Munkholm P, Langholz E, Binder V. Investigations of inheritance of chronic inflammatory bowel disease by complex segregation analysis. $B M \mathcal{F}$ 1993; 306: $20-4$. 